\title{
Correction to: Obesity, change of body mass index and subsequent physical and mental health functioning: a 12-year follow- up study among ageing employees
}

Anna Svärd ${ }^{1 *}$, Jouni Lahti ${ }^{1}$, Eira Roos ${ }^{1}$, Ossi Rahkonen ${ }^{1}$, Eero Lahelma ${ }^{1}$, Tea Lallukka ${ }^{1,2}$ and Minna Mänty ${ }^{1,3}$

\section{Correction}

After publication of the article [1], it has been brought to our attention that obesity has been incorrectly defined in the parameters below Tables 2, 3 and 4. As already in Table 1, it should be defined as $\geq 30 \mathrm{~kg} / \mathrm{m} 2$. The original version of the article has been revised to reflect this.

\footnotetext{
Author details

'Department of Public Health, Faculty of Medicine, University of Helsinki, (Tukholmankatu 8B), P.O. Box 20, 00014 Helsinki, Finland. ${ }^{2}$ Finnish Institute of Occupational Health, Helsinki, Finland. ${ }^{3}$ Laurea University of Applied Sciences, Unit of Research, Development and Innovation, Vantaa, Finland.
}

Received: 4 October 2017 Accepted: 5 October 2017

Published online: 17 October 2017

\section{Reference}

1. Svärd A, Lahti J, Roos E, Rahkonen O, Lahelma E, Lallukka T, et al. Obesity, change of body mass index and subsequent physical and mental health functioning: a 12-year follow-up study among ageing employees. BMC Public Health. 2017;17(1):744. https://doi.org/10.1186/s12889-017-4768-8.

\footnotetext{
* Correspondence: anna.svard@helsinki.fi

'Department of Public Health, Faculty of Medicine, University of Helsinki,

(Tukholmankatu 8B), P.O. Box 20, 00014 Helsinki, Finland
} 